\title{
The management of primary adenocarcinoma of the vermiform appendix
}

\author{
K. T. HESKETH ${ }^{1}$ \\ From the Department of Surgery, Hammersmith Hospital and Postgraduate \\ Medical School, London
}

EDITORIAL SYNOPSIS Primary adenocarcinoma of the appendix is not of low grade malignancy as has been previously supposed and a right hemicolectomy is the proper procedure, offering a much better prognosis than simple appendicectomy.

Primary adenocarcinoma of the appendix is rare and likely to pass unrecognized. The diagnosis is usually made by a histologist, unless at operation the disease is so advanced that its nature is unquestioned. It is the purpose of this paper to describe several new cases and to examine past experiences of this tumour as a guide to treatment and prognosis.

Tumours of the appendix constitute only 0.3 to $0.4 \%$ of all intestinal growths and during the last century were regarded as metastases although Merling (1838) and Rokitansky (1867) both described primary tumours of the appendix. Kelly and Hurdon (1905) in their large text on the appendix offered a classification of these tumours. Their illustrations show three typical argentaffin tumours, one adenocarcinoma, and one probable sarcoma. Collins (1955) surveyed 50,000 human appendices mostly removed for appendicitis. His series embraces almost 100 disease classifications including 18 malignant conditions.

Many estimates of the incidence of this carcinoma are found in the literature, varying from $0.5 \%$ to $3.0 \%$ of appendicectomies. None of these estimates is based on large series and they must vary with local histological classification. Two extensive series are available, both from the United States. Norment (1932) in a survey of 45,000 appendices reported 67 'carcinomas'. Two of these are grouped apart as 'atypical' columnar-celled growths and were probably adenocarcinomas. The histological description of the remaining 65 leaves little doubt that they were argentaffin tumours. Collins (1955) found $0.08 \%$ in 50,000 cases; this possibly represents the incidence.

In 1955 in England and Wales it is estimated that 117,000 persons had their appendix removed and if the figures in Hammersmith Hospital are any guide 'Present address: c/o British Military Hospital, Singapore
TABLE I

NUMBER OF APPENDICECTOMIES PERFORMED DURING 10 YEARS IN DEPARTMENT OF SURGERY, HAMMERSMITH

\begin{tabular}{lccr} 
Year & $\begin{array}{c}\text { HOSPITAL } \\
\text { 'Primary' } \\
\text { Operations }\end{array}$ & $\begin{array}{c}\text { 'Incidental } \\
\text { Operations }\end{array}$ & Total \\
\hline 1949 & 280 & 27 & 307 \\
1950 & 260 & 40 & 300 \\
1951 & 240 & 40 & 280 \\
1952 & 230 & 30 & 260 \\
1953 & 255 & 20 & 275 \\
1954 & 310 & 21 & 331 \\
1955 & 240 & 10 & 250 \\
1956 & 220 & 43 & 263 \\
1957 & 270 & 86 & 356 \\
1958 & 220 & 65 & 285 \\
& & & 2,907
\end{tabular}

(Table I) this number is fairly constant each year. In the United Kingdom only 12 cases of adenocarcinoma of the appendix which fulfil strict criteria have been reported in the 30 years before this paper. In this department over the past ten years $2,52.5$ 'primary' appendicectomies have been performed and to these must be added 382 'incidental' operations done during the course of gynaecological or other abdominal procedures. During this period one case of adenocarcinoma has arisen (case 1).

Previous writers have commented on the confused state of the literature concerning this tumour. In 1906 Rolleston and Jones produced the first extensive account and collected a series of cases including that of Beyer (1882) who described what has come to be regarded as the first authentic case. They also included cases by men famous in the history of the appendix-Battle and McBurney. However, no clear histological classification emerges from this and none of these cases is included here partly due to lack of histological evidence, and also because the treatment 
and prognosis of acute, uncomplicated appendicitis has altered so much in the past half century as to minimize the value of these early cases.

Frauenthal and Grausman (1933), describing a case, mentioned 360 previous accounts, a figure far in excess of anything subsequently accepted. At the other extreme, Young and Wyman (1942) questioned all but four earlier reports, two from the United States and two from Germany. In 1943 Uihlein and McDonald re-assessed histologically 144 cases seen over a 30 -year period at the Mayo Clinic, confirming only five.

The earliest case report quoted here is 1929 but most of the others have been in the last five years. The older accounts are less easy to evaluate properly and follow-up reports impossible to obtain.

Notwithstanding the publications that have appeared, as recently as 1953 Clarke and Simonds commented that little was known regarding the frequency, route, and extent of metastases, or of the prognosis of carcinoma of the appendix and the best surgical procedures for dealing with it.

\section{HISTOLOGICAL CLASSIFICATION}

Difficulty arises with the histology of the adenocarcinoma and the confusion with the argentaffin carcinoma commonly known as the 'carcinoid'. In their paper of 1943 Uihlein and McDonald produced the following classification which has provided a standard for several subsequent authors: 1 Carcinoid type, 2 cystic type, and 3 colonic type.

1 CARCINOID TYPE Willis (1948) prefers to call these argentaffin carcinomas 'lest we disguise their inherent malignant nature'. They were shown in 1914 to have the property of reducing ammoniacal silver salts to silver and are now well recognized as a distinct entity. Masson (1928) gave a classical description of these tumours. Their golden-yellow colour is almost constant and they tend to be multicentric in origin. The cells may be biochemically active, secreting 5-hydroxytryptamine and causing a clearly defined syndrome.

2 CYSTIC TYPE Cystic type or mucocele of the appendix was first recognized by Rokitansky in 1842. Although included in their classification by Uihlein and McDonald, it is not clear that this is a distinct entity and there is certainly no evidence that it is always of a malignant nature. Willis says that to produce a mucocele one does not require a neoplastic process and Aird does not regard the mucocele as necessarily malignant.

Woodruff and McDonald (1940) had discussed this. From 43,000 appendices removed over a 24- year period at the Mayo Clinic they abstracted 146 cases of mucocele: 136 of these were simple and in 10 were due to early neoplastic hyperplasia of the mucosa similar to that seen in McCollum's cases (V.I.). It could be suggested that in these cases the overgrowth of the mucosa provides a mechanical factor which leads to the production of a mucocele. The condition may be produced experimentally by mechanical means.

3 COLONIC TYPES The colonic type or adenocarcinoma behaves similarly to other colonic carcinomas being either polypoid or ulcerative.

Attempts have been made to subdivide the adenocarcinomas into several grades; this is unrealistic in small series and produces statistically insignificant figures.

It has been written that the site of the lesion gives a clue to its nature: that the adenocarcinoma is to be found in the proximal third and that the distal thirds are the province of the argentaffin tumour. In a high proportion of reports here the site of the tumour is not reported. This prevents any conclusion but 22 $(23 \%)$ cases of adenocarcinoma are recorded in the proximal third and $38(34 \%)$ in the distal thirds. Thirty-five $(37 \%)$ were not recorded. When the tumour is found at the proximal extreme of the appendix it is a matter of opinion whether it arises in the appendix or the caecum: one or two doubtful cases of this category have been discarded.

There are certain anatomical features of the appendix which affect the progress of the disease. The narrow lumen is soon occluded by even a small growth, which may precipitate an acute obstructive appendicitis. This is the usual picture and may cause a number of carcinomas to be removed at an early stage, and to go unnoticed. The appendix is also covered by peritoneum and extensive soiling of the peritoneal cavity easily occurs if the appendix perforates; this is the commonest site for metastases.

The material for this series has been collected from the reports mostly in the British, Canadian, and United States literature with the addition of a few others. A total of 95 cases has been selected for analysis (Table II). Many, especially those described in the earlier papers, have been discarded as not fulfilling the conditions of the present enquiry which has been limited to invasive tumours, reasonably believed to be adenocarcinomata and penetrating beyond the submucosa. To these have been added the new cases described. There are several reports of the tumour confined to the mucosa but it is difficult to draw a line between a simple hyperplasia and this very early form of malignancy when reading some of the reports.

Those workers who had not already recorded the 
TABLE II

DETAILS OF INDIVIDUAL CASES

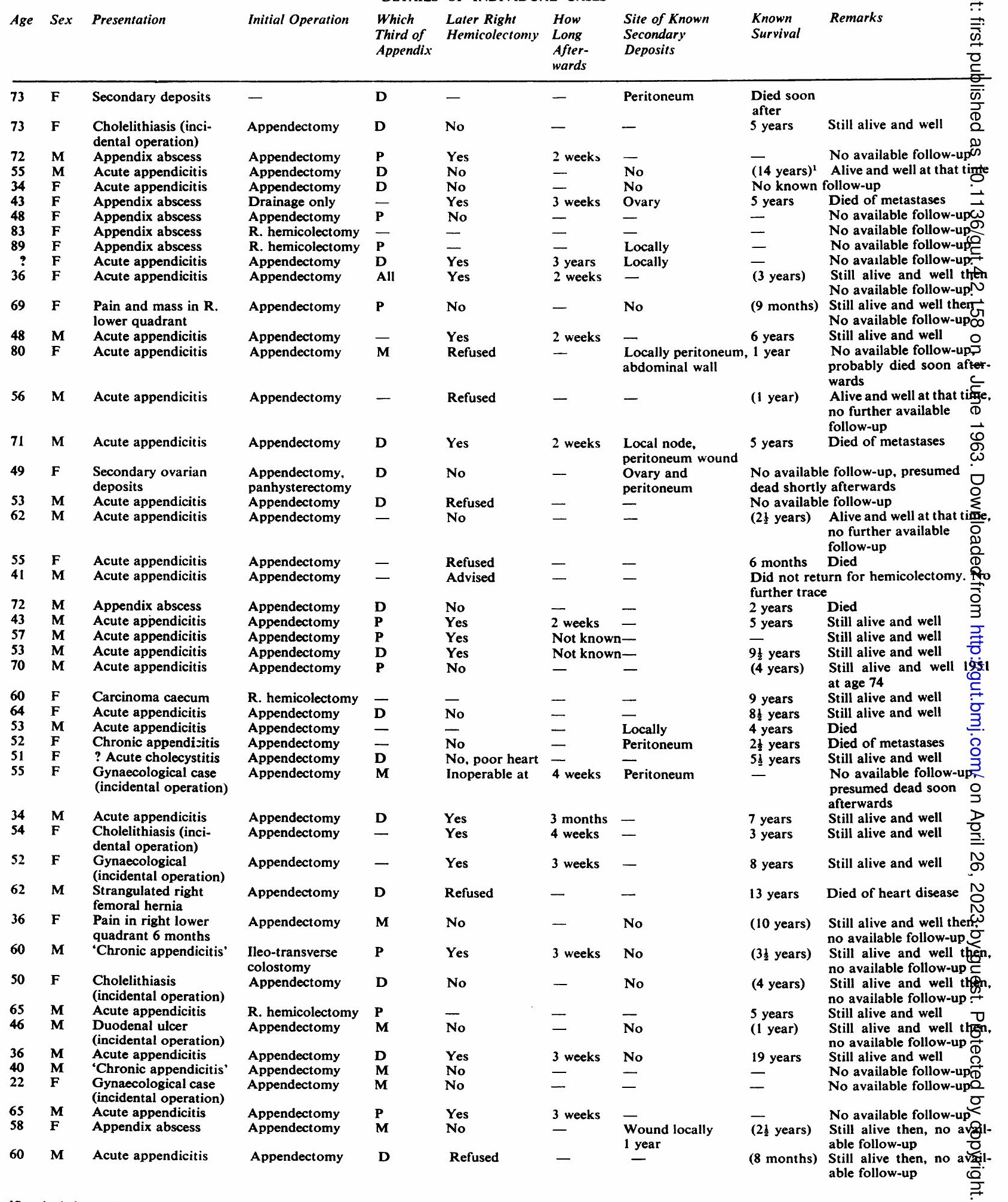


TABLE II continued

DETAILS OF INDIVIDUAL CASES

Age Sex Presentation

$\begin{array}{lllllll}\text { Initial Operation } & \begin{array}{l}\text { Which } \\ \text { Third of } \\ \text { Appendix }\end{array} & \begin{array}{l}\text { Later Right } \\ \text { Hemicolectomy }\end{array} & \begin{array}{l}\text { How } \\ \text { Long } \\ \text { After- } \\ \text { wards }\end{array} & \begin{array}{l}\text { Site of Known } \\ \text { Secondary } \\ \text { Deposits }\end{array} & \begin{array}{c}\text { Known } \\ \text { Survival }\end{array} & \text { Remarks } \\ & & & & \end{array}$

\begin{tabular}{|c|c|c|}
\hline 56 & $\mathbf{M}$ & Appendix abscess \\
\hline 42 & $\mathbf{F}$ & $\begin{array}{l}\text { Gynaecological case } \\
\text { (incidental appendectomy }\end{array}$ \\
\hline 54 & $\mathbf{F}$ & Appendix abscess \\
\hline 41 & $\mathbf{F}$ & $\begin{array}{l}1 \frac{1}{2} \text { years pain in right } \\
\text { lower quadrant }\end{array}$ \\
\hline 51 & $\mathbf{M}$ & Secondary deposits \\
\hline 57 & $\mathbf{M}$ & Carcinoma caecum \\
\hline 40 & $\mathbf{F}$ & Intestinal obstruction \\
\hline 49 & $\mathbf{F}$ & $\begin{array}{l}\text { Gynaecological case } \\
\text { (incidental operation) }\end{array}$ \\
\hline 64 & $\mathbf{M}$ & Acute appendicitis \\
\hline
\end{tabular}

72 M Acute appendicitis

26 F Acute appendicitis

67 F Acute appendicitis

43 F Gynaecological case

$61 \mathrm{M}$ (incidental operation)

79 M Acute appendicitis

$\begin{array}{lll}51 & F & \text { Acute appendicitis } \\ 56 & F & \text { Intestinal obstruction }\end{array}$

Appendectomy

Appendectomy

$\mathbf{P}$

R. hemicolectomy -

Appendectomy

5 weeks
8 weeks

Wound at 3 years 4 years

Yes
Yes

Died

years
$7 \frac{1}{2}$ years

Still alive and well

$P$ No

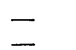

Peritoneum

2 years

Died

R. hemicolectomy D

No

R. hemicolectomy D -

- Peritoneum

Peritoneum

21 years Died

Appendectomy - $\quad$ No

Appendectomy D

No

- Local nodes

3 years

Died shortly afterwards

- Local nodes

8 years

Appendectomy $\quad P \quad$ No

Appendectomy $\mathbf{M} \quad$ Yes

$\begin{array}{lll}\text { R. hemicolectomy } & M & - \\ \text { Appendectomy } & \text { D } & \text { No }\end{array}$

Ovary

10 months Died

- $\quad-$

Appendectomy

Appendectomy

M Refused

Appendectomy

$\bar{D} \quad \overline{\text { No }}$

Appendectomy

Acute appendicitis

Acute appendicitis

Appendectomy

$\overline{\mathbf{D}} \quad \overline{\mathrm{Y}}$

R. hemicolectomy

Carcinoma of caecum

42

46 M Acute appendicitis

$47 \quad M \quad$ Mass in right lower quadrant

Appendectomy $\quad \mathbf{P} \quad$ No

R. hemicolectomy $\mathbf{P}$

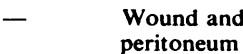

$1 \underline{1}$ years

Believed dead

一

7 weeks

8 weeks -

$8 \frac{1}{2}$ years

8 years

25 years

Died from abdominal

abscess

Still alive and well

- $\quad$ -

Still alive and well

Glands, lungs

pleura, and peritoneum

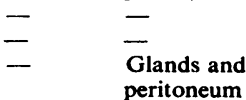

2 years

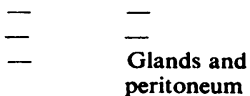

3 days

Still alive and well

Died soon after

Peritoneum

6 months

Died of C.V.A.

Died ? renal failure

-

- Died soon after

Glands, colon,

wound

Nodes, lungs, liver, 10 months

No available follow-up

No available follow-up

peritoneum

Peritoneum

Peritoneum

4 months

Died

$\begin{array}{lll}- & \text { Peritoneum } \\ \text { - } & \text { Peritoneum }\end{array}$

6 months

Died

59 M Cholelithiasis

(incidental operation)

63 M Acute appendicitis

Appendectomy

Do

Appendectomy

All thirds No

Appendectomy M No

Appendectomy

$P \quad$ No

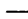

7 months

Omentum,

peritoneum

Peritoneum

No

Appendectomy

Acute appendicitis

F Right lower quadrant

pain for 3 weeks

Acute appendicitis

Acute appendicitis

Acute appendicitis

Acute appendicitis

43 M Appendix abscess

61 F Acute appendicitis

68 F Secondary deposits

47 F Appendix abscess

$\begin{array}{lll}41 & \text { M } & \text { Acute appendicitis } \\ 60 & \text { M } & \text { Acute appendicitis }\end{array}$

39 M Acute appendicitis

51 M Acute appendicitis

51 F Mass in right iliac fossa

17 F Six months pain in

right iliac fossa

63 F Secondary ovarian

deposits

$42 \quad M \quad$ Pain in right iliac

fossa

72 F Appendix abscess

? F Acute appendicitis

54 F

Acute appendicitis

Appendectomy
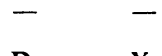

Appendectomy

Appendectomy

Appendectomy

Appendectomy

Appendectomy

Appendectomy

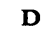

Yes

No

No

No

Inoperable

Yes

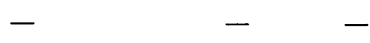

R. hemicolectomy -

Appendectomy

Appendectomy

$\begin{array}{lll}\text { Appendectomy } & - & \text { No } \\ & & \text { Yes }\end{array}$

R. hemicolectomy $P$

Appendectomy

Biopsy

Appendectomy

R. hemicolectomy Appendectomy -

R. hemicolectomy -
-
-
No
No
No
Yes
-
Yes

Yes

Yes

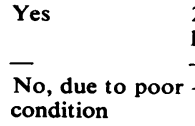

3 months

Died despite deep $x$-ray therapy

10 months Died

$2 \frac{1}{2}$ months Died other causes

6 weeks Died after laparotomy ? no obvious cause

6 years Still alive and well

3 days Died peritonitis

2 years Died

2 years Still alive and well

Died of peritonitis

3 months Died

2 weeks Died C.V.A.

Died soon afterwards

(excised)

Glands and

peritoneum

'Survival times shown in parentheses are those patients known to have lived for that period but are not up to date (1959). 
death of a patient have all been circularized to bring the follow-up figures up to date.

\section{DIAGNOSIS}

The diagnosis has never been established before operation and it will be seen that this condition most commonly presents as an acute obstructive appendicitis. Forty-two $(44 \%)$ of the cases here presented as acute appendicitis, a further $13(14 \%)$ as appendix abscesses, and $8(11 \%)$ as 'chronic appendicitis'. These together comprise $66 \%$ of all cases. Eight cases $(11 \%)$ presented in a terminal phase with widespread metatases.

As many as $13(14 \%)$ patients had an 'incidental' appendicectomy with subsequent histological discovery of an adenocarcinoma. A pre-operative diagnosis of cholelithiasis or a gynaecological disorder had without exception been made and sustained at operation. No attempt has been made to classify these cases separately.

\section{AGE AND SEX INCIDENCE}

The age incidence and range is shown graphically (Fig. 1). The youngest subject is 17 years old. The age group 40-65 years is most commonly affected but no age group appears immune.

There is no sex predominance of any significance, there being 49 female patients and 45 males.

\section{TREATMENT}

When we come to treatment, we found in this Unit

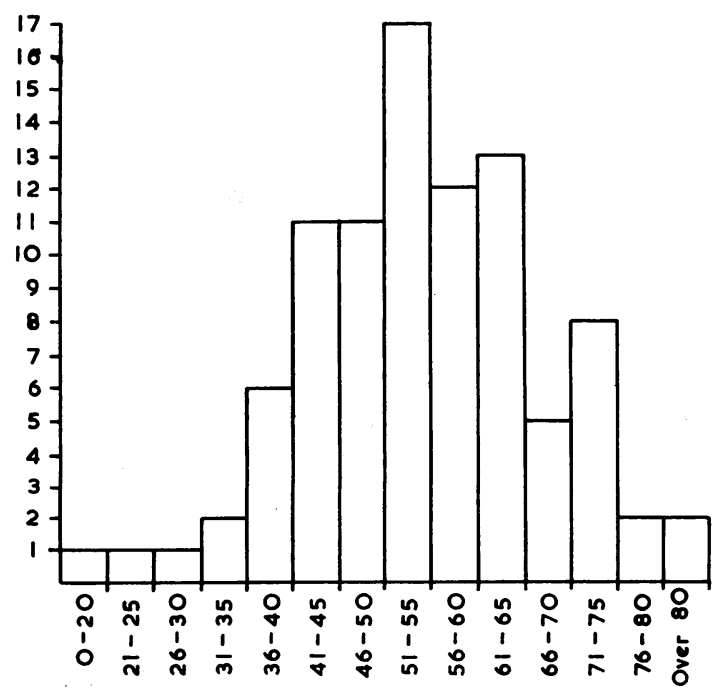

FIG. 1. Histogram of age incidence and range. that no one had first-hand experience of this disease and faced with such a growth found by appendicectomy (case 1) the decision to do a formal right hemicolectomy was originally founded on basic principles. A brief survey of some of the literature at that time did little to help. Authors were divided as to the proper measures to adopt. This more extensive analysis has attempted to show that the proportion of cases in which a hemicolectomy has been done has risen appreciably in the last few years. One could infer from this that the more radical operation is becoming accepted as a proper form of treatment. There still remains the problem of direct 'seeding' of the peritoneal cavity but it would seem that this is unavoidable.

The treatment at the moment is essentially surgical. Only two patients were given radiotherapy, one in the United States and case 2 reported in the United Kingdom. The first was dead of the disease in seven months and in the other instance only a short palliative course was given because of intestinal obstruction and rapid deterioration. Deep $x$-ray therapy has probably no more obvious application in cases of adenocarcinoma of the appendix than in carcinomas of the colon.

From the point of view of treatment let us consider a total of 87 cases, omitting those eight presenting in a terminal stage.

Of these $87,15(17 \%)$ had a right hemicolectomy as a primary procedure when the nature of the disease was recognized at the initial operation. Twenty-five (28\%) had a hemicolectomy as a secondary procedure a week or so after. This would allow proper preparation of the patient. For 12 patients $(14 \%)$ a further resection was proposed but was not carried out either because of the patient's condition or because consent to operation was refused. Radical surgery was thus proposed in $60 \%$ of the cases and carried out in $46 \%$. Those remaining had an appendicectomy only. Two of these also had a local resection of the caecum.

McCollum et al. (1957), in considering those tumours confined entirely to the mucosa (V.S.), were of the opinion that appendicectomy would suffice. Growths of this type have not been considered here but the anatomical structure of the organ raises grave doubts whether a distinction can be drawn in their treatment. The muscular layers of the appendix are often deficient at several points where the submucosa becomes adjacent to the serosa.

Adenocarcinoma of the appendix has bzen referred to previously as one of low-grade malignancy but the cases reviewed suggest that it behaves as aggressively as any other colonic cancer although it differs in some respects. Transcoelomic spread occurs readily and produces peritoneal and ovarian secondary de- 
posits. By their nature these multiply rapidly and appear to be lethal before extensive hepatic metastases are established. Few references are found to secondary deposits in the liver. Adjacent lymph nodes are commonly involved and serve as a strong motive for radical surgery. Local recurrence is also quite common both intraperitoneally and in the wound. This has occurred despite hemicolectomy and sometimes several years after operation.

\section{PROGNOSIS}

In assessing the prognosis, the 18 patients known to have died of intercurrent disease, and those presenting with secondary deposits or dying within three months of operation have been excluded. The remainder of the patients has been divided into two groups, those in whom a simple appendicectomy was performed and those who had a right hemicolectomy. Two expressions of the prognosis have been used. First, 5 and 10-year survivals for each group are given, and

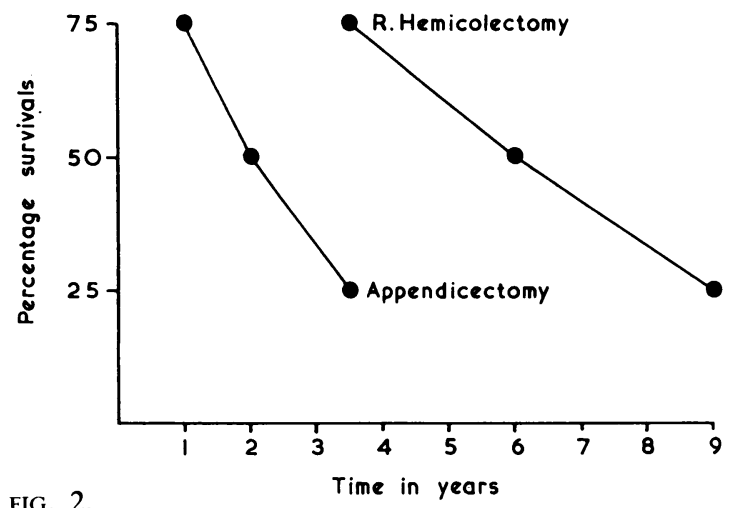

FIG. 2.

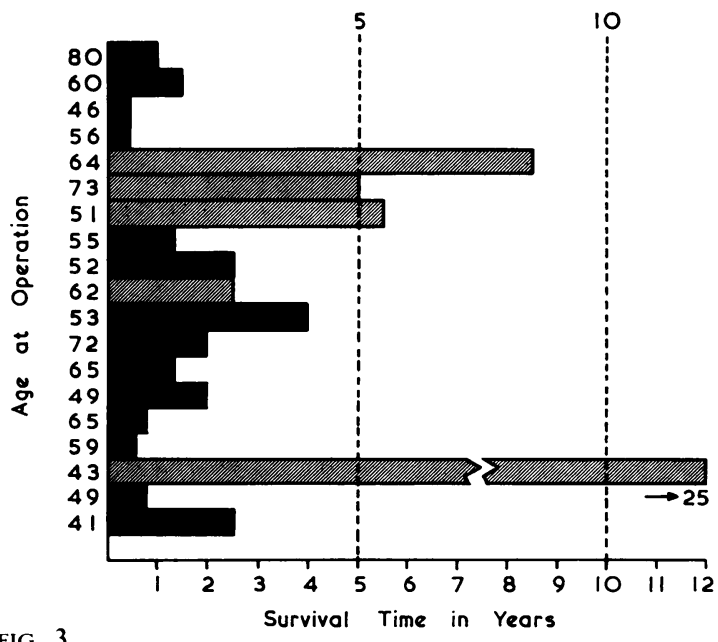

secondly the 'median survival time' is given for each group, i.e., the time at which $50 \%$ of the patients remain alive; these are plotted with the times at which $75 \%$ and $25 \%$ remain alive, and give a much better idea of the pattern of survival and enable better comparison of techniques (Fig. 2).

From Fig. 2 it will be seen that the survival curve for the cases submitted to more radical surgery is shifted well to the right and is much less steep. It should be remembered also that this improved prognosis is underemphasized by this graph as twothirds of the patients are still alive. Nineteen cases where only appendicectomy was performed have been followed up to date (Fig. 3); of these 14 (75\%) died of the disease. There are four survivors $(20 \%)$ reaching or exceeding five years. The other group comprises 31 cases in which right hemicolectomy was undertaken and for which current follow-up reports are available (Fig. 4). Ten deaths $(33 \%)$ are reported. Nineteen $(63 \%)$ patients survived for five years or

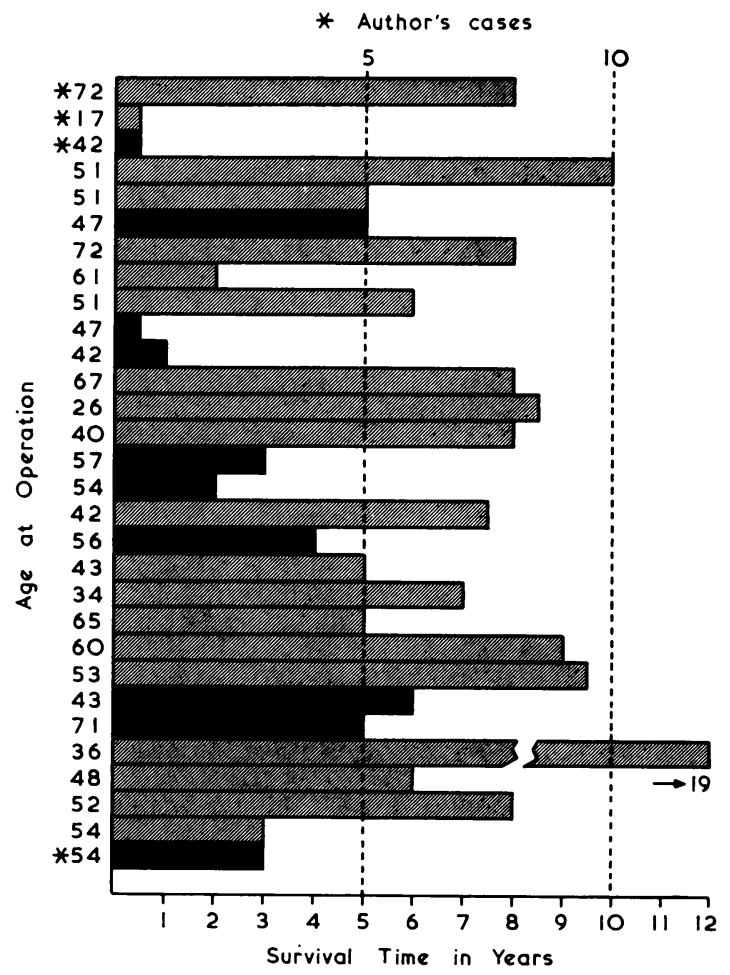

FIG. 4 .

FIG. 2. Survival times for patients subjected to appendicectomy and to right hemicolectomy.

FIGS. 3 and 4. Survival times of five years and over for both groups followed up to date. 
more including two $(8 \%)$ exceeding 10 years. In both groups all but one of the deaths which have occurred have been in the first five-year period.

\section{CASE REPORTS}

CASE 1 This girl, aged 17 , was first seen as an outpatient on 10 December 1958, complaining of abdominal pain. She stated that she had been quite well until six months previously when she began to have attacks of sharp, central abdominal pain, often radiating to the right lower quadrant, and lasting perhaps half an hour at a time. Until recently she had had approximately two attacks a week but for the past eight weeks she had had pain almost every day. During these last weeks also she had periods of diarrhoea every two or three days when she passed three or four loose stools a day with no blood or mucus. There was nothing untoward in her previous or family history, and clinical examination produced no abnormal physical signs (pulse 80, blood pressure 150/75 $\mathrm{mm}$. $\mathrm{Hg}$ ). A contrast enema at this time showed a free flow of barium around the colon, the terminal ileum also filled: no abnormality was shown. The urine was normal.

On 21 January 1959 she was admitted and the next day a normal-looking appendix was removed through a right Lanz incision. Nothing else was found at the time in the

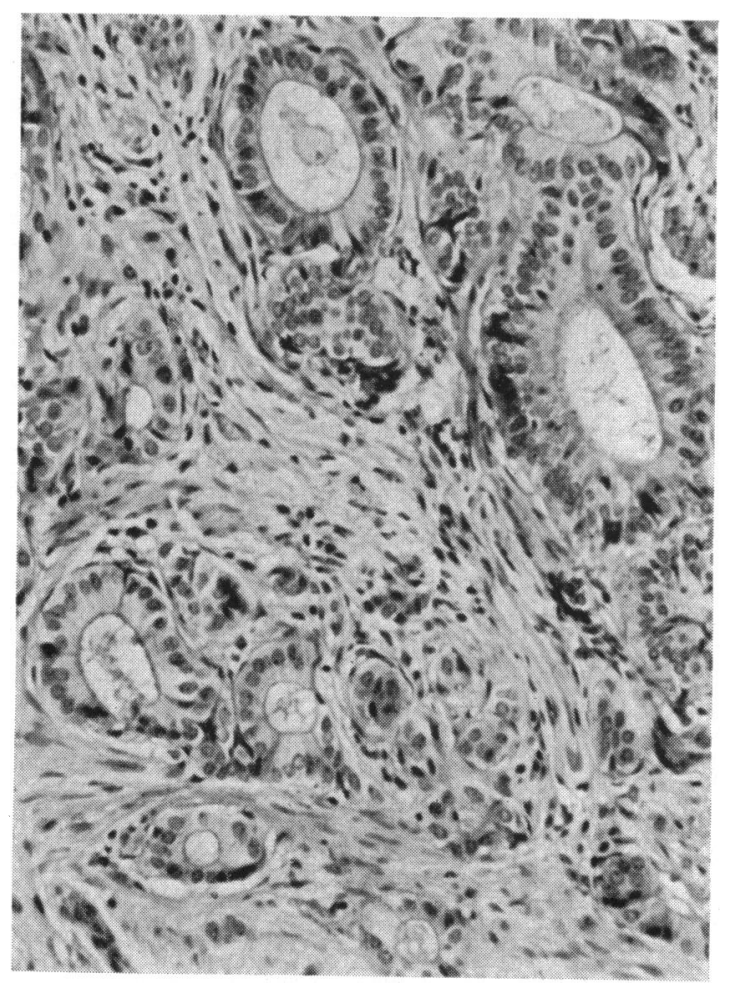

FIG. 5. Case 1: A section showing invasion of the muscular layers of the appendix wall by the tumour $(\times 240)$. abdomen to account for her symptoms. A sigmoidoscopy was also done but nothing abnormal was seen. She made an uneventful recovery.

Histology 'An externally normal appendix $4.5 \mathrm{~cm}$. long $\times 0.5 \mathrm{~cm}$. diameter shows no evidence of acute or chronic inflammation. In the tip of the appendix is a tumour composed of columnar cells in well-formed tubules separated by a fibrous stroma, forming a nodule $2 \mathrm{~mm}$. in diameter. Strands of tumour are invading the muscular coat. Occasional Paneth cells were seen in the tumour near the mucosa. Having failed to demonstrate the presence of argentaffin granules by either the silver or Diazo techniques and in the presence of many tubular acini, a diagnosis of an adenocarcinoma was made' (Fig. 5).

It was agreed that more radical surgery was necessary. At this stage it was difficult to correlate her marked symptoms with such a relatively small lesion but following appendicectomy they had all resolved.

On 24 March 1959, through a right Rutherford Morison incision, the ascending colon was found to be freely mobile. There were a number of enlarged, soft nodes in the mesocolon. No obvious secondary deposits were found. The right colon was mobilized and removed together with the proximal third of the transverse colon and distal six inches of the ileum. An end-to-end anastomosis was performed between ileum and transverse colon and the mesenteric defect repaired. The wound was closed without drainage.

Histological examination of the excised bowel, including 17 lymph nodes, disclosed no tumour. She made an uneventful recovery and when last seen in the follow-up clinic was quite well.

CASE 2 This man, aged 42, gave a history of three attacks of pain during the previous six years which had been diagnosed as appendicitis but treated conservatively. Following the last attack he was advised to have his appendix removed and this was done on 5 December 1955. Histological examination showed the epithelium to be replaced by a well-differentiated adenocarcinoma and the wall was extensively invaded through to the serosa by much less differentiated adenocarcinoma (Figs. 6 and 7).

On 16 December 1955 a right hemicolectomy was performed and this specimen when submitted to section showed poorly differentiated adenocarcinoma with numerous mitoses situated in the muscular layers of the caecum with an intact mucosa over it (Fig. 8). A lymph node also showed secondary deposits of adenocarcinoma (Fig. 9.)

Two months later he was found to have a local recurrence of the tumour. He was referred for radiotherapy but had had only one treatment when he developed intestinal obstruction. At laparotomy a large carcinomatous mass was found, some $12 \mathrm{~cm}$. across, in the right lower quadrant, with small masses scattered throughout the peritoneal cavity; one of these was involving and obstructing the small bowel. Masses were also found in the liver. After operation he was given a short palliative dose of irradiation with little change in the size of the mass. On his return home he died three weeks later-only seven months after the appendicectomy. 


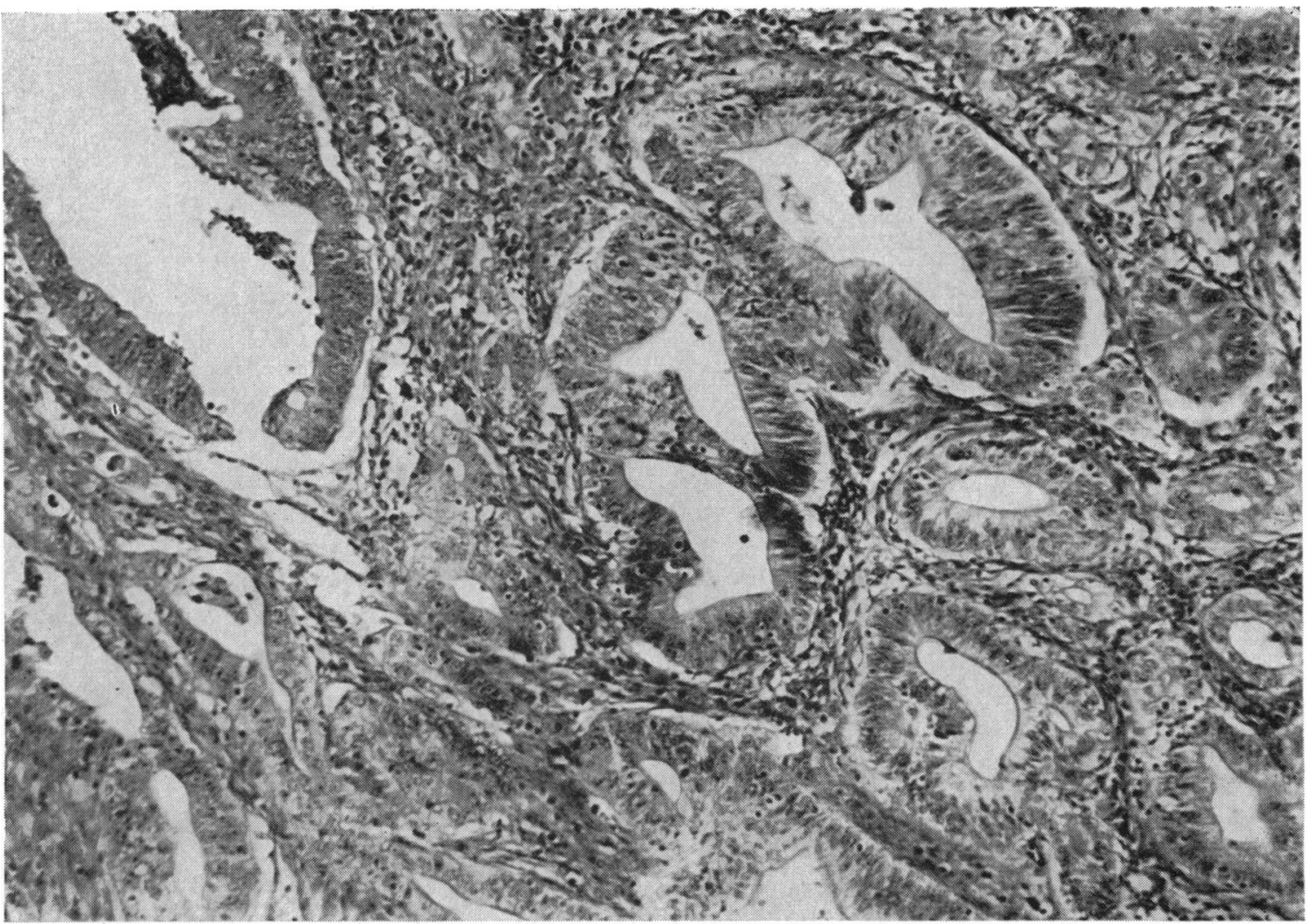

FIG. 6. Case 2: The typical appearance of the adenocarcinoma seen here in a section from the wall of the appendix. This section shows marked glandular formation, numerous mitoses, reduplication of the 'mucosal' layers, and an overall irregular pattern $(\times 160)$.

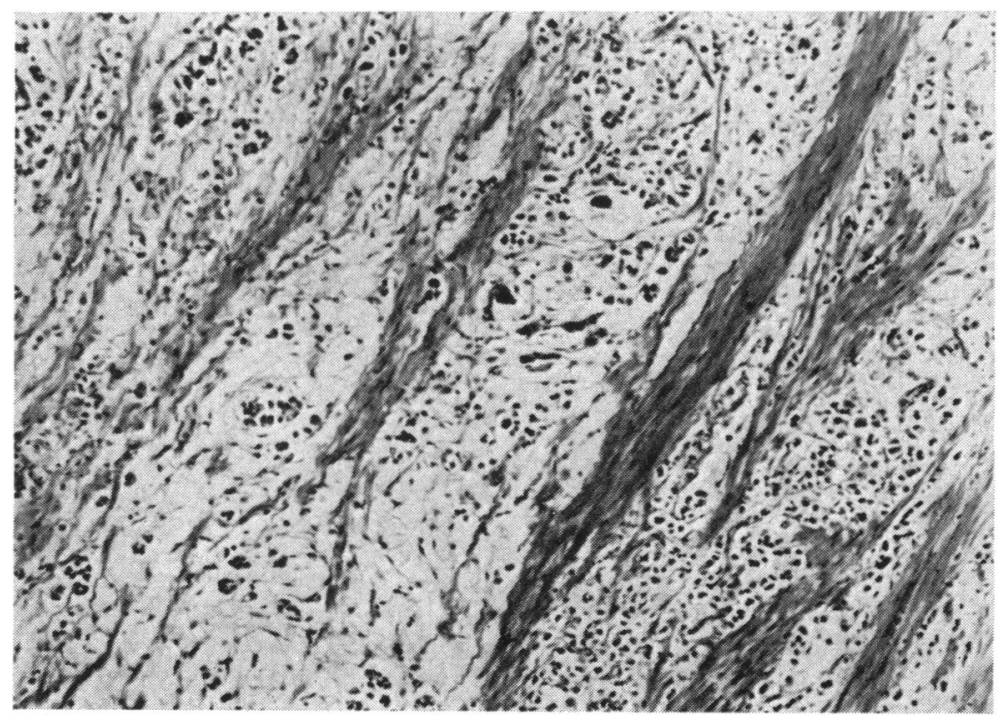

Fig 7. Case 2: Showing the spread of tumour in the mesoappendix $(\times 80)$. 


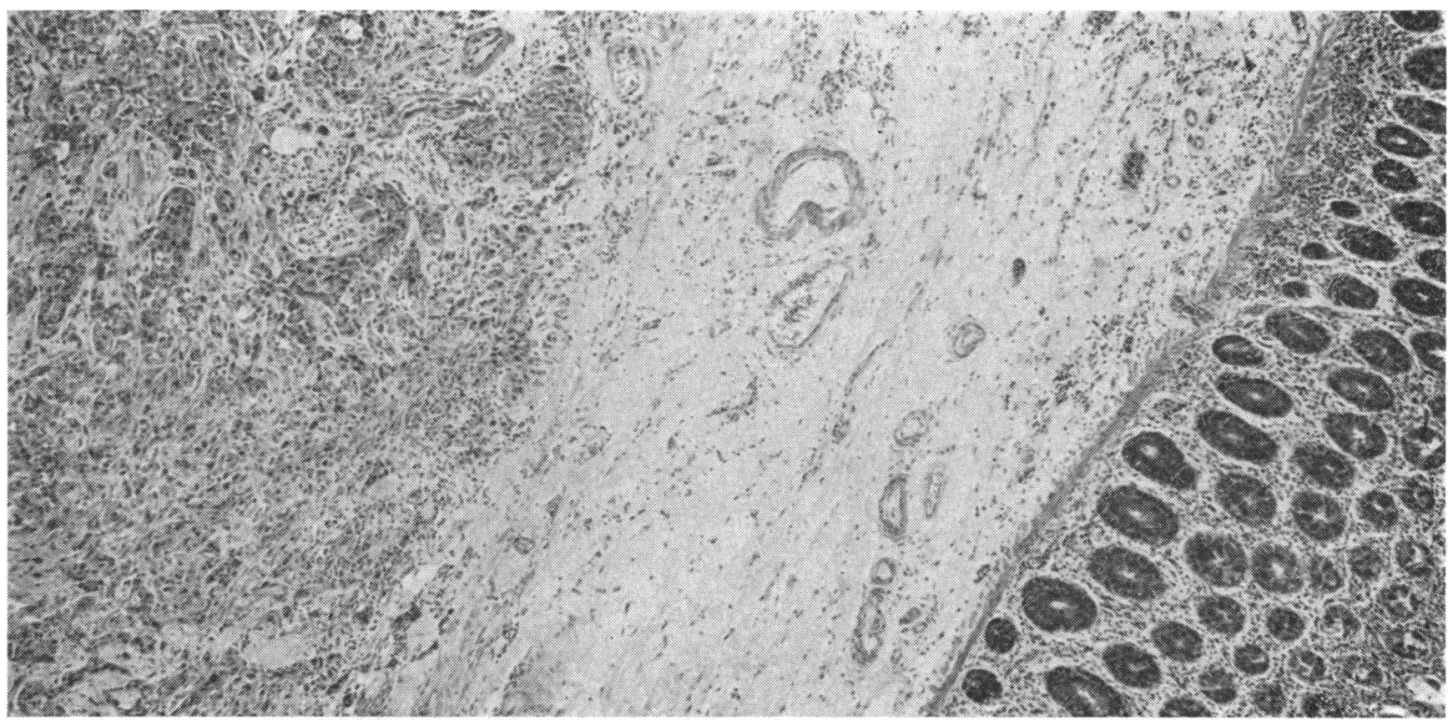

FIG. 8. Case 2: Metastatic deposits of adenocarcinoma in the wall of the caecum with intact caecal mucosa. This is taken from the hemicolectomy specimen $(\times 60)$.

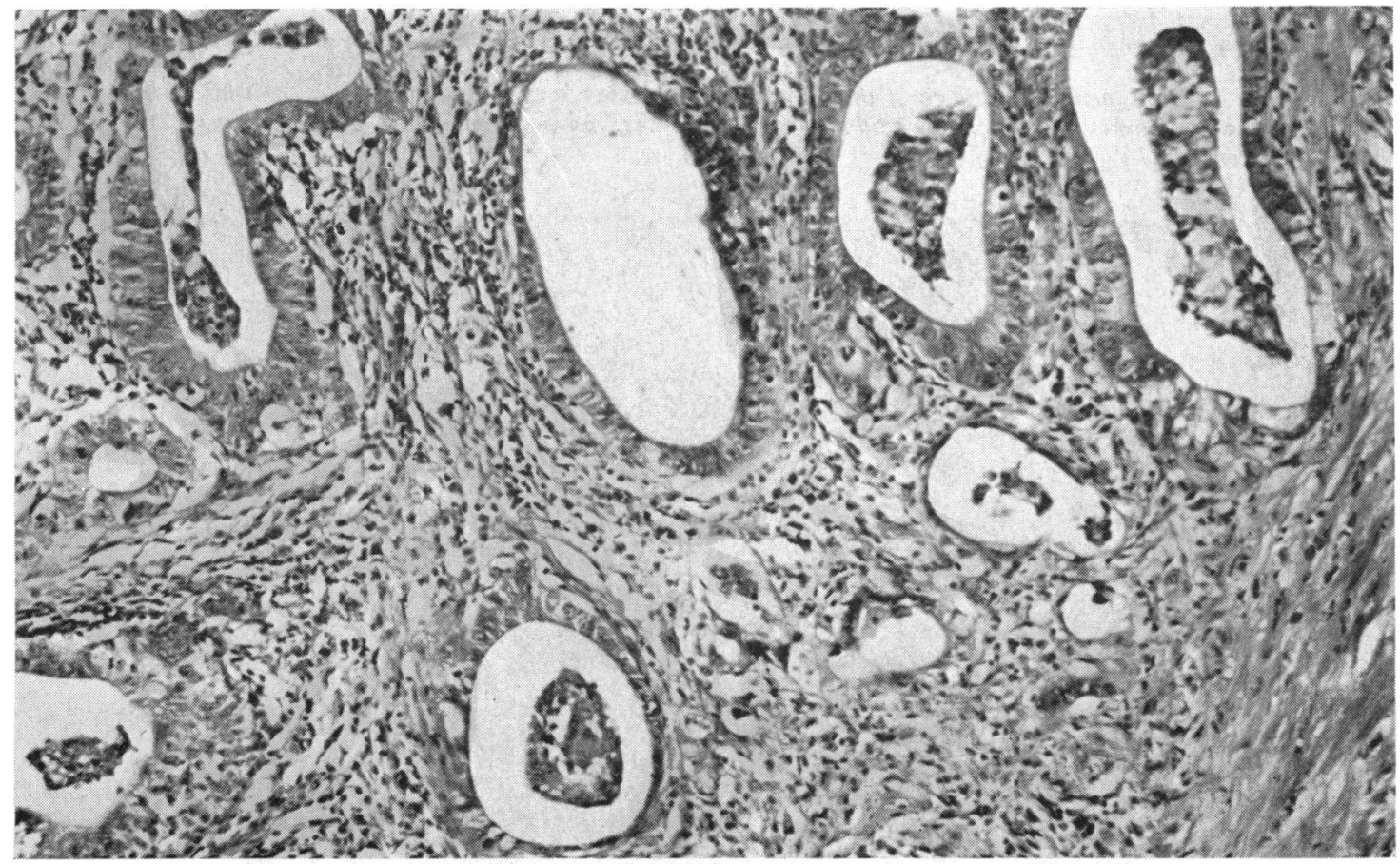

FIG. 9. Case 2: Metastatic deposits of adenocarcinoma in a lymph node removed at hemicolectomy $(\times 160)$. 


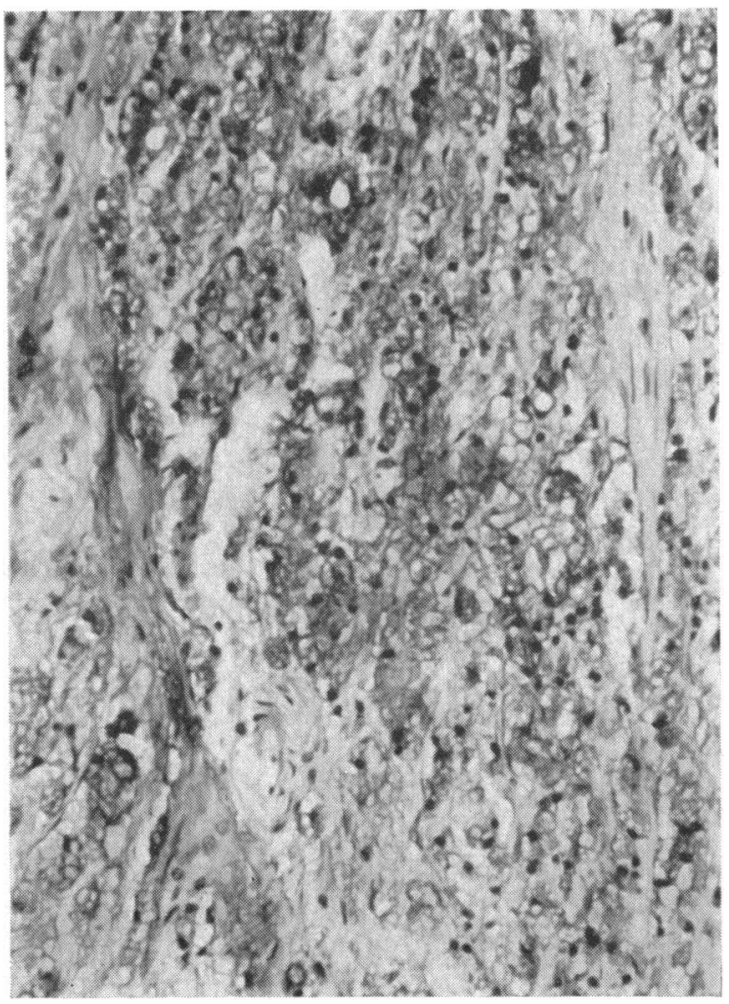

FIG. 10. Case 3: A section of ovary showing deposits of adenocarcinoma $(\times 80)$.

CASE 3 This woman, aged 64, presented in November 1944 , complaining of abdominal enlargement and pain for the previous six weeks together with loss of appetite and loss of weight. She was found to have bilateral, firm abdominal masses arising from the pelvis, and at subsequent laparotomy one week later these were found to be inoperable ovarian tumours. A biopsy was taken which was reported as a secondary deposit of degenerate mucoid carcinoma (Figs. 10 and 11), probably from a primary centre in the colon or stomach.

A year later she was readmitted in a moribund condition and died two days later. Necropsy revealed a primary adenocarcinoma of the appendix with massive secondary deposits in both ovaries and peritoneum.

CASE 4 This woman, aged 72, presented in October 1951, and pre-operatively a diagnosis of chronic appendicitis with resolving abscess was made. The malignant nature of her condition was appreciated at operation and a right hemicolectomy was performed as a primary procedure. From this she made an uneventful recovery and she is still alive and well.

Histological examination of the tumour showed an adenocarcinoma of the appendix.

CASE 5 This woman (age not recorded) presented in 1954 with acute appendicitis for which her appendix was

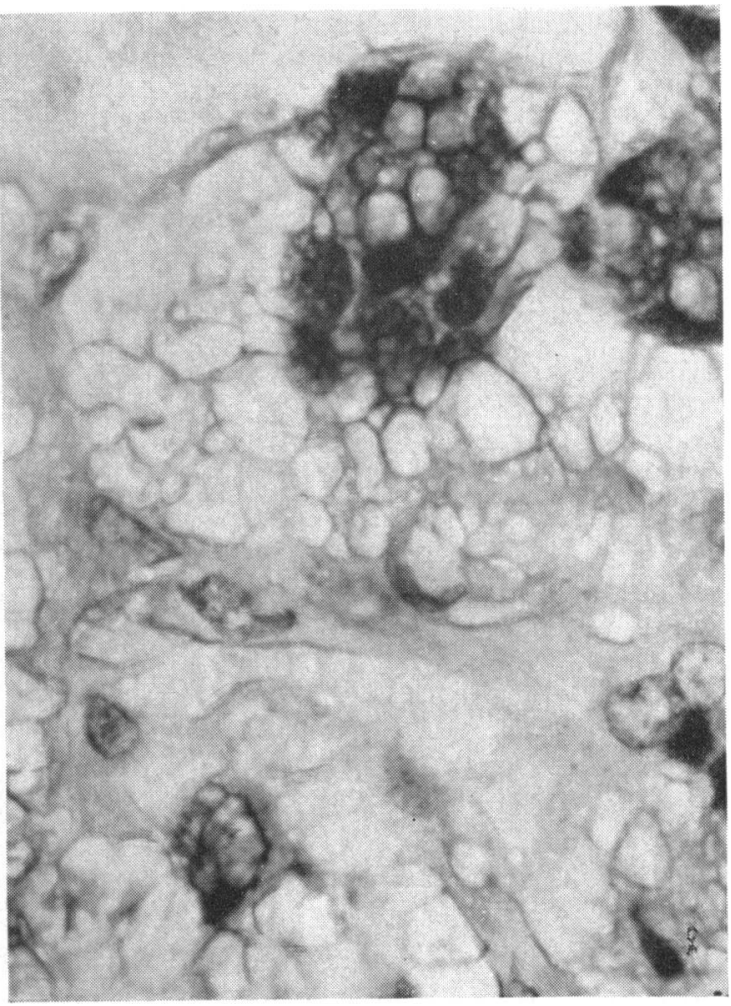

FIG. 11. Case 3: A high-powered view of the ovarian metastasis shown in Fig. $10(\times 1,000)$.

removed; this was shown to contain an adenocarcinoma. No further operation or treatment was instituted in view of her poor general condition and mental instability, for which she had previously had a pre-frontal leucotomy some years before.

This patient survived eight months with a gradually increasing mass in the right lower quadrant: she died suddenly and it was thought that she had a coronary thrombosis. No necropsy was made.

CASE 6 This woman, aged 54, was operated upon in 1954 for acute appendicitis and at operation a carcinoma of the appendix was found. A right hemicolectomy was performed as a primary procedure and she remained well for 18 months when her abdomen was re-explored because of intestinal obstruction. This was found to be due to a stenosis of the anastomosis and she appeared quite free of tumour at that time. However, a year later she again had an obstruction and a palpable mass in the right lower quadrant; she refused operation and settled after conservative treatment. She died six months later. No necropsy was performed.

I am most indebted to the late Professor Ian Aird for his encouragement in the preparation of this work and to Mr. K. P. S. Caldwell of Exeter for cases 4, 5, and 6.

A special debt must be acknowledged to all those 
authors who have written previously on this subject and some of whom have gone to endless trouble to answer my many letters enquiring after their patients.

Thanks are also due to Professor C. V. Harrison and the Department of Morbid Anatomy, to the Department of Medical Illustration for the tables and photomicrographs, and to the Royal Society of Medicine for some obscure references and translations.

I must also acknowledge the permission of the Medical Director-General of the Royal Navy to publish.

\section{REFERENCES}

Aird, I. (1957). A Companion in Surgical Studies. Livingstone, Edinburgh.

Clarke, R. G., and Simonds, J. P. (1953). Adenocarcinoma of the appendix: report of two cases. Amer. J. dig. Dis., 20, 47-50.

Collins, D. C. (1955). A study of 50,000 specimens of the human vermiform appendix. Surg. Gynec. Obstet., 101, 437-445.

Frauenthal, M., and Grausman, R. I. (1933). Primary carcinoma in the vermiform appendix. Amer. J. Surg., 19, 118-119.
Kelly, H., and Hurdon, E. (1905). The V'ermiform Appendix and its Diseases. Saunders, Philadelphia.

McCollum, M. (1957). Adenocarcinoma of the appendix. Grace Hosp. Bull. (Detroit), 35 (1), 39.

Masson, P. (1928). Carcinoids (argentaffin-cell tumors) and nerve hyperplasia of the appendicular mucosa. Amer. J. Path., 4, $181-211$.

Merling (1838) and Rokitansky (1867) quoted by Weaver, C. H. (1957). Amer. J. Surg., 36, 523.

Norment, W. B. (1932). Tumors of the appendix. Surg. Gynec. Obstet., 55, 590-596.

Public Health Monograph No. 38. U.S. Treasury Dept.

Rolleston, H. D., and Jones, L. (1906). Primary malignant disease of the vermiform appendix. Med. Chir. Trans., 89, 125-156.

Registrar-General's Returns. (1959). General Register Office.

Uihlein, A., and McDonald, J. R. (1943). Primary carcinoma of the appendix resembling carcinoma of the colon. Surg. Gynec. Obstet., 76, 711-714.

Willis, R. A. (1948). Pathology of Tumours. Butterworth, London.

Woodruff, R., and McDonald, J. R. (1940). Benign and malignant cystic tumors of the appendix. Surg. Gynec. Obstet., 71, 750-755.

Young, E. L., and Wyman, S. (1942). Primary carcinoma of the appendix associated with acute appendicitis. Report of a case New Engl. J. Med., 227, 703-705.

\section{The March 1963 Issue}

\section{THE MARCH 1963 ISSUE CONTAINS THE FOLLOWING PAPERS}

Electron microscopic changes associated with water absorption in the jejunum A. WYNN WILLIAMS

Post-operative absorption of water from the small intestine L. F. TINCKLER and W. KULKE

A case of jaundice due to unilateral hepatic duct obstruction with relief after hepatic lobectomy STEVEN MISTILIS and LEON SCHIFF

A comparison of the use of Aldactone and Aldactone A in the treatment of hepatic ascites STANLEY SHALDON, JILL A. RYDER, and MYRON GARSENSTEIN

Liver disease and ammonia intoxication KENNETH $S$. WARREN and STEVEN SCHENKER

Torsion of the gall bladder R. K. GREENWOOD

Duodenal diverticula and haemorrhage M. J. s. LANGMAN

The reliability and reproducibility of the Schilling test in primary malabsorptive disease and after partial gastrectomy J. F. ADAMS and E. JUNE CARTWRIGHT

The influence of diet on the quality of faecal fat in patients with and without steatorrhoea JOAN P. W. WEBB, A. T. JAMES, and T. D. KELLOCK

Studies in dogs on the biphasic nature of the gastric secretory response to hypoglycaemia and other stimuli with special reference to the role of the adrenals $W$. SIRCUS, C. J. W. HUSTON, R. M. PRESHAW, H. BASSÖE, and R. A. HARKNESS
1 The pattern of the biphasic response and the relation to gastric innervation and to hypoglycaemia

2 The relationship of the gastric secretory response to hypoglycaemia and to changes in the level of plasma cortisol

3 The effect of bilateral adrenalectomy

4 The interrelationship of the phases of the response and the role of the antrum

The pancreas and gastric secretion: failure of pancreatectomy to prevent inhibition of gastric secretion by secretin JOSEPH A. KENNEDY and GEORGE A. HALLENBECK

A 5-hydroxytryptophan-secreting carcinoid tumour A. C. P. CAMPBELl, A. H. GOWENLOCK, D. S. PLATT, and P. J. D. SNOW

Histochemistry of the gastric mucosa J. PINTO CORREIA, M. ISABEL FILIPE, and J. COSTA SANTOS

1 In normal mucosa

2 In pathological conditions and in changes induced by histamine

Studies on the effect of vagotomy on small intestinal motility using the radio-telemetering capsule B. ROSs, B. W. WATSON, and A. W. KAY

Localization of intestinal bleeding using a miniature Geiger counter B. MCKIBBIN and B. W. WATSON

British Society of Gastroenterology

Gastroenterological Society of Australia

Copies are still available and may be obtained from the PUBLISHING MANAGER, BRITISH MEDICAL ASSOCIATION, TAVISTOCK SQUARE, W.C.I., price 18s. 6D. 